\section{Girls Like to Chat with me If There is a Piece of Bupropion Under My Tongue}

\section{Gökben Hızlı Sayar' ${ }^{1}$ Eylem Özten ${ }^{1}$}

${ }^{1}$ Uskudar University, NPIstanbulHospital, Psychiatry Department, Istanbul-Turkey

Journal of Mood Disorders 2014;4(3):142

\section{Dear Editor,}

Bupropion enhances both noradrenergic and dopaminergic neurotransmission via reuptake inhibition of the norepinephrine transporter and the dopamine transporter. In addition, its mechanism of action may involve the presynaptic release of norepinephrine and dopamine. Due to its dopaminergic profile, it has mildly stimulating properties and its dopaminergic effect could influence reward mechanisms in addictive states. Although in 1980's in a clinical essay it was concluded that, despite bupropion's reinforcing properties in animals, the compound is not amphetamine-like and is unlikely to give rise to such abuse in humans (1), there are a few reports of recreational use of bupropion (3).

A 32-years old male patient admitted to emergency room with the complaint of palpitation that had been started after taking bupropion $50 \mathrm{mg}$ sublingually and continuing for last 3 hours. He had a past history of treatment of bupropion $150 \mathrm{mg} / \mathrm{d}$ withthe diagnosis of depression. Although his psychiatrist changed his regimen to escitalopram due to treatment resistance, he continued bupropion on an irregular basis. He claimed that bupropion provided him an euphoria similar to that attained from cocaine. He reported a regular use of cocaine 4 years ago, but for the last 4 years he did not use any illegal drugs. He was not on any regular medications.

He described his bupropion use as: "At first I took the

\section{References:}

1. Griffith JD, Carranza J, Griffith C, Miller LL. Bupropion: clinical assay for amphetamine-like abuse potential. Clin Psychiatry. 1983;44:206-8.

2. Spiller HA, Bottei E, Kalin L. Fatal bupropion overdose with post mortem blood concentrations. Forensic Sci Med Pathol 2008;4:47-50. bupropion by nasal way. Afterwards I used bupropion tablet in little pieces (1/3 of a tablet) sublingually as Ifelt "down" during the day. After taking $1 / 3$ tablet of bupropion sublingually, I felt euphoric for 3-4 hours, but as the effects were wearing off I had another 1/3 tablet again, ending up with a total daily dose of $450 \mathrm{mg}$. It makes me "up", I can work better, I am a bit social phobic normally but after taking bupropion I become talkative and all girls like to chat with me if there is a piece of bupropion under my tongue."

On arrival, he had a heart rate of $124 \mathrm{bpm}$ and blood pressure of 170/90 mmHg. His ECG and neurological examination were normal. On drug plasma level monitoring, $157 \mathrm{ng} / \mathrm{mL}$ bupropion found (therapeutic range is $50-100 \mathrm{ng} / \mathrm{mL}$ ). No other drugs or alcohol were detected by using a broad toxicology screen. He was discharged with advices about recreational drugs and their use.

Although recreational use of bupropion is rare, due to life threatening adverse effects of bupropion intoxication (2), it must be fully defined. This case illustrates also the difference between intranasal or sublingual versus oral administration of bupropion.After oral administration bupropion undergoes extensive first-pass hepatic metabolismby a rate of $95 \%$. When taken by intranasal or sublingual route the alteration in bupropion disposition may lead to increased plasma levels due to lack of firstpass metabolism. Psychiatrists should keep in mind recreational abuse potential of bupropion and different routes of administration especially in patients who have abuse potential.

\section{Gökben Hızlı Sayar}

Uskudar University, NPIstanbulHospital, Psychiatry Department, Istanbul-Turkey

ghizli@uskudar.edu.tr

This letter was accepted for publication in May 27, 2014.

3. Kim D, Steinhart B. Seizures induced by recreational abuse of bupropion tablets via nasal insufflation. CJEM. 2010;12:158-61. 